\title{
Estratégias Competitivas e Prioridades Competitivas da Manufatura: um Estudo Exploratório
}

\author{
Silvio R. I. Pires
}

Doutor em Engenharia de Produção, professor do mestrado em Engenharia de Produção da UNIMEP

\section{Oswaldo L. Agostinho}

Doutor em Engenharia Mecânica, professor da EESC/USP

\author{
UNIMEP \\ Rodovia Santa Bárbara/Iracemápolis, km 1.5, Santa \\ Bárbara d'Oeste, SP, 13450-000, fone (0194) 632311, \\ fax (0194) 228204
}

Palavras chave: Estratégia da Manufatura, Estratégia Competitiva, Prioridades Competitivas da Manufatura, Planejamento e Controle da Produção

Key words: Manufacturing Strategy, Competitive Strategy, Manufacturing Competitive Priorities, Production Planning and Control

\section{RESU MO}

No processo de redescoberta da Manufatura presenciado nos últimos anos, vários têm sido os trabalhos publicados clamando pela necessidade de se tratar a mesma sempre sob uma ótica estratégica dentro das empresas.

Sob este contexto, este trabalho relata sobre o conceito de Estratégia da Manufatura e sobre a estrutura lógica de uma modelo de integração das atividades de Planejamento e Controle da Produçāo a uma Estratégia da Manufatura, proposto pelos autores. A proposta principal do artigo é apresentar alguns dados de uma pesquisa de campo realizada em 12 empresas representativas operando no estado de São Paulo, no tocante às suas Estratégias Competitivas e Prioridades Competitivas da Manufatura.

Os dados mostram principalmente que o conceito de Estratégia da Manufatura, tal como está aqui formalizado, era praticamente desconhecido pelas empresas, havendo muito pouca integraçāo da Manufatura com as Unidades de Negócios as quais ela pertencia.

\section{ABSTRACT}

In the process of re-discovering of Manufacturing observed in the last years, many works have been published claiming that it is necessary to deal with Manufacturing always under a strategic vision in the company.

At this context, this paper relates about the Manufacturing Strategy concept and about a logic framework of a model of integration of Production Planning and Control in a Manufacturing Strategy, proposed by this authors. The main proposal of this paper is to show some dates of an exploratory research, made in twelve representative companies operating in São Paulo State about theirs Competitive Strategies and Manufacturing Competitive Priorities.

The results of this research show mainly that the companies presented an incipiente diffusion of Manufacturing Strategy concepts and a small integration between the Manufacturing and its Business Unit. 


\section{Introdução}

No processo de redescoberta da Manufatura vivenciado nos últimos tempos, várias têm sido as opções tecnológicas e gerenciais colocadas à disposiçāo dos dirigentes industriais. Infelizmente, decisōes sobre tais questões são muitas vezes tomadas apenas sob a ótica operacional e de curto prazo, sem se observar adequadamente os aspéctos competitivos e estratégicos da empresa.

Isso significa considerar que as decisōes sobre a Manufatura devem necessariamente estar sempre integradas com as decisões estratégicas da organização. Para tal, a organização deve definir claramente como vai inserir seus produtos no mercado e competir com eles, bem como vai atingir seus objetivos satisfatoriamente.

Nessa linha de pensamento, um conceito relativamente recente tem ganho espaço a nível mundial: o conceito de Estratégia da Manufatura.

Segundo vários autores, as pesquisas teóricas e empíricas já realizadas na área estão apenas começando. Apesar disso, a literatura existente caminha no sentido de se chamar a atenção para a necessidade de haver uma maior integração da Manufatura com os objetivos da organização, bem como tem se ocupado em traçar um bom panorama para se visualizar a Manufatura nos dias atuais. Todavia, uma das características marcantes dessa literatura tem sido a de que, ao mesmo tempo em que clama pela necessidade de se integrar (ligar) adequadamente a Manufatura aos objetivos e demais elementos da organização, ela ainda trata muito superficialmente os caminhos e metodologias que podem levar a essa desejada integração.

Pires (1994) propōe um modelo conceitual de integração das atividades de Planejamento e Controle da Produção a uma Estratégia da Manufatura, complementado com um estudo de casos em algumas empresas representativas do estado de Sāo Paulo. Este artigo tem como objetivo principal mostrar alguns dados relevantes dessa pesquisa de campo.

\section{o Conceito de Estratégia da Manufatura}

A criação do conceito de Estratégia da Manufatura ("Manufacturing Strategy") é relativamente recente e é freqüentemente atribuida ao trabalho do pesquisador norteamericano Wickham Skinner (1969), publicado na Harvard Business Review, numa época em que a decadência da economia industrial dos EUA era visível, principalmente no tocante à perda de competitividade de seu parque industrial.

Durante o período áureo da supremacia econômica dos EUA, principalmente após a Segunda Guerra Mundial, as questōes ligadas à Manufatura foram, em geral, por eles negligenciadas. Por exemplo, em 1958 o reputado economista John Kenneth Galbraith afirmava que os EUA tinham resolvido seus problemas com a Manufatura. Em seu trabalho pioneiro, Skinner (1969) relata que a origem dessa decadência remonta ao início deste século, quando a alta direção das indústrias norte-americanas parou de considerar as questōes ligadas à Manufatura sob uma visão estratégica, considerando-as praticamente já resolvidas.

O termo Estratégia da Manufatura tem sido definido de forma complementar nos últimos tempos. Resumidamente pode-se afirmar que uma Estratégia da Manufatura deve envolver o desenvolvimento e desdobramento dos recursos da Manufatura em total alinhamento com os objetivos e estratégias da empresa, sendo colocada como sendo o uso efetivo dos pontos fortes da Manufatura como uma arma competitiva para se obter os objetivos da Corporação e da Unidade de Negócios. O posicionamento da mesma dentro de uma estrututura hierárquica das estratégias empresariais é ilustrado pela figura 1 .

Uma Unidade de Negócios ("Business Unit") pode ser representada por uma divisão, por uma empresa, por uma unidade fabril ou por uma linha de produtos dentro de uma Corporação.

A Estratégia da Unidade de Negócios, ou apenas Estratégia de Negócios, geralmente trata do escopo/limites de cada $\mathrm{Ne}$ - 


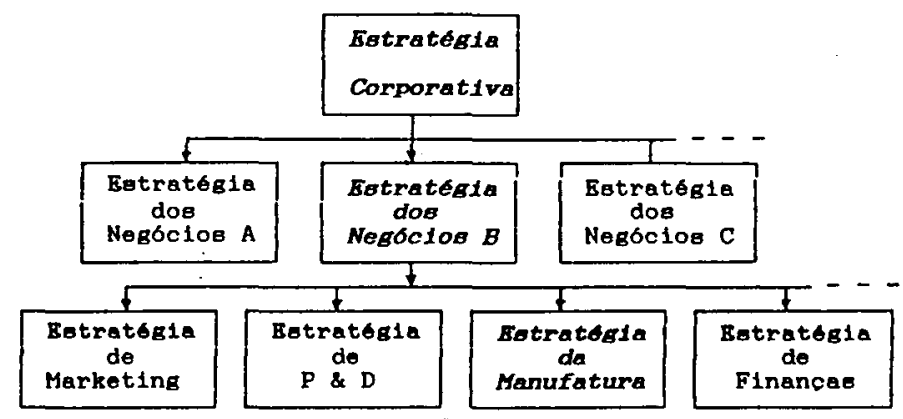

Figura 1: Hierarquia das Estratégias Empresariais

gócio e suas ligações com a Estratégia Corporativa e descreve as bases nas quais a Unidade de Negócios irá obter e manter uma vantagem competitiva.

Nesse nível o "modelo" mais utilizado é o proposto por Porter (1985), através do qual uma empresa pode obter uma vantagem competitiva de duas formas básicas. Ela pode buscar a liderança no custo (menor custo que pode levar a prática de menores preços) ou através da diferenciação de seus produtos (e poder praticar seus preços com um pouco mais de liberdade).

Uma Estratégia da Manufatura deve fundamentalmente se ater a dois componentes básicos: as Prioridades Competitivas e as chamadas questōes estruturais e infra-estruturais da Manufatura, conforme ilustra a figura 2.
As Prioridades Competitivas podem ser definidas como sendo um conjunto consistente de prioridades que a Manufatura terá para competir no mercado, durante um certo horizonte de tempo. Não devem, portanto, ser confundidas com as estratégias competitivas genéricas utilizadas a nível da Unidade de Negócios.

$\mathrm{Na}$ atualidade, as prioridades mais utilizadas mundialmente são o Custo (menor custo de produção), a Qualidade (sob a ótica de satifação dos clientes), a Flexibilidade (principalmente no tocante ao mix e volume de produção) e o Desempenho das Entregas (busca de menores prazos e grau de confiabilidade dos mesmos). Um grande ponto de discussão ainda aberto sobre essas Prioridades é a questão das incompatibilidades ("trade-offs") entre elas e a respeito de eventuais seqüências de implementação das mes-

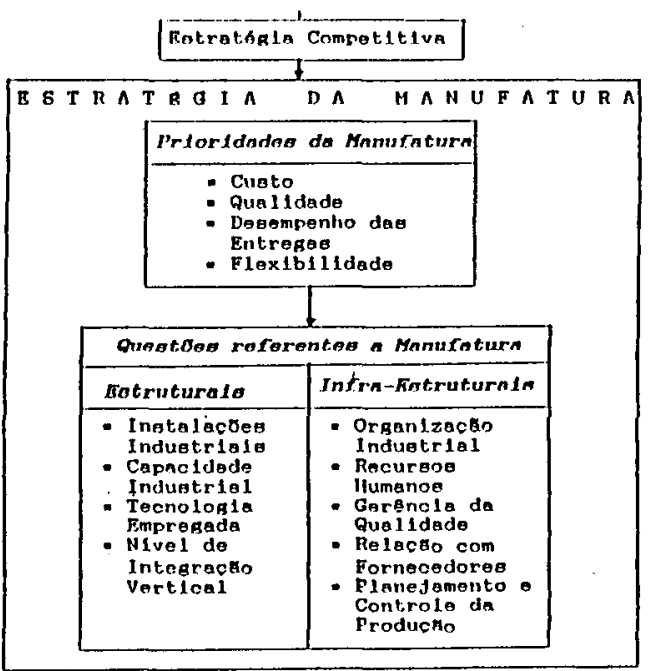

Figura 2: Conteúdo de uma Estratégia da Manufatura 
mas. Por exemplo, alguns pesquisadores argumentam que as empresas japonesas têm procurado se qualificar primeiro com relação a qualidade. Para terem um baixo custo elas precisam se qualificar com um nível mínimo de qualidade e confiabilidade nas entregas. Já para obterem flexibilidade precisam se qualificar primeiro nessas três Prioridades Competitivas.

As questões básicas estruturais e infra-estruturais referem-se a uma série de questōes sobre a estrutura e infra-estrutura da Manufatura que devem ser adequadamente levantadas e resolvidas dentro do processo de formulação de qualquer Estratégia da Manufatura.

Assim, após as definições a respeito das Prioridades Competitivas, ou iterativamente com elas, uma Estratégia da Manufatura deve se ater adequadamente a essas questões. O primeiro autor a formalmente se preocupar com essas questões, dentro da formulação de uma Estratégia da Manufatura, foi Steven Wheelwright (1984), chamando a atenção principalmente para a necessidade de consistência entre as decisões tomadas sobre as mesmas.

\section{Modelo de Integração Proposto}

A lógica do modelo de integração das atividades de Planejamento e Controle da Produção a uma Estratégia da Manufatura proposto pelos autores pode ser visualizado através da figura 3.

Todo o modelo conceitual está baseado na definição de uma Prioridade Competitiva primária da Manufatura durante um certo horizonte de tempo, sem que isso signifique que as outras Prioridades Competitivas devam ser menosprezadas, conforme sugere precisamente o conceito de "Focused Facto$r y^{\prime \prime}$ proposto por Skinner (1974).

Esse modelo proposto considera também que as atividades de Planejamento e Controle da Produção, além de se orientarem pelas Prioridades Competitivas da Manufatura e terem uma relação de interdependência com as questōes estruturais e infra-estruturais da mesma, mantêm uma forte dependência de outros dois parâmetros referenciais básicos da Manufatura. Esses parâmetros são:

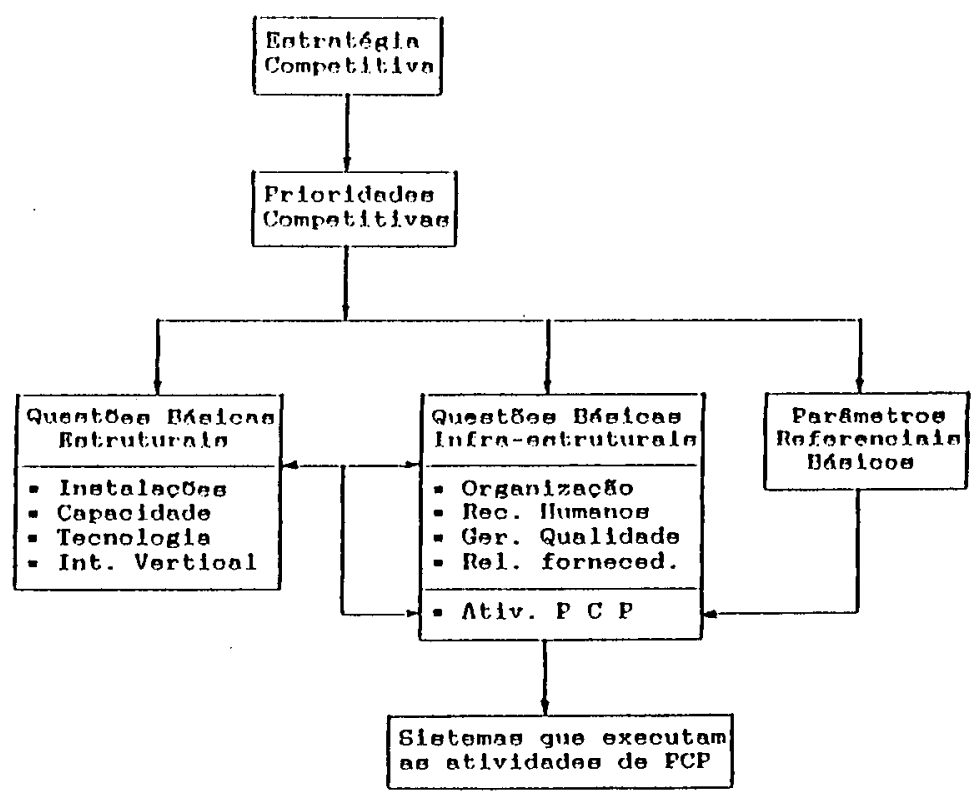

Figura 3: Lógica do modelo de integração proposto Pires (1994) 
- as possíveis formas de interação entre o sistema produtivo e os clientes externos, as quais podem se dar nas formas MTS (Make to Stock - Produção para Estoque), ATO (Assemble to Order - Montagem sob Encomenda), MTO (Make to Order - Produção sob Encomenda) e ETO (Engineering to Order - Engenharia sob Encomenda);

- o nível de diversificação e variabilidade no mix de produtos produzidos.

O modelo proposto possui uma estrutura de desenvolvimento tipicamente "top-down" e se preocupa, simultâneamente, com o processo e conteúdo de uma Estratégia da Manufatura.

No âmbito deste artigo, porém, interessa discutir apenas a respeito do primeiro nível de integração tratado pelo modelo, exatamente da integração entre as Estratégias Competitivas e as Prioridades Competitivas primárias da Manufatura.

Tomando então as duas Estratégias Competitivas básicas (menor custo e diferenciação dos produtos) e as quatro Prioridades Competitivas consideradas no trabalho (Custo, Qualidade, Desempenho das Entregas e Flexibilidade), poderia haver oito combinações entre elas, conforme ilustra a análise matricial ilustrada pela figura 4 .

Analisando-se cada uma dessas combinaçōes, principalmente sob a realidade industrial brasileira, supõe-se que a combinação:

$(1,1)$ : seja perfeitamente concordante;

$(1,2)$ : seja possível, porém, de difícil conciliação;
$(1,3)$ :seja possível para o caso de interação com os clientes nas formas MTS e ATO, desde que os custos dos estoques não sejam representativos;

$(1,4)$ : seja teoricamente possível através de tecnologias como os FMS, porém supostamente ainda distante da realidade industrial do país;

$(2,1)$ : seja de difícil conciliação;

$(2,2)$ : seja perfeitamente concordante;

$(2,3)$ : seja perfeitamente concordante;

$(2,4)$ : seja perfeitamente concordante.

Destas oito combinaçōes possíveis considerou-se que, sob a realidade industrial brasileira, apenas quatro delas sejam perfeitamente, ou mais facilmente, concordantes. Numa primeira análise exclui-se a combinação 2.1 , provavelmente ainda impraticável em todo o mundo industrializado. Posteriormente exclui-se as combinaçōes $1.2,1.3 \mathrm{e}$ 1.4 , as quais requerem situaçōes e tecnologias de produção ainda inacessíveis à grande maioria das indústrias, principalmente as aqui instaladas.

Pode-se entāo resumir a discussāo feita neste tópico afirmando-se que supostamente existiriam quatro combinações perfeitamente viáveis (ou mais viáveis) entre as estratégias competitivas de uma Unidade de Negócios e as Prioridades Competitivas da Manufatura (considerando-se apenas a Prioridade primária). A figura 5 ilustra estas combinações.

O modelo de integração proposto serviu então de base para a realização de uma pes-

\begin{tabular}{|c|c|c|c|c|}
\hline \multirow[b]{2}{*}{$\begin{array}{l}\text { Betrateria } \\
\text { Competitiva }\end{array}$} & \multicolumn{4}{|c|}{ Priortdade Compotitiva } \\
\hline & Custo & Qual1dade & $\begin{array}{c}\text { Desempenho } \\
\text { das Entregas }\end{array}$ & Flexibllidade \\
\hline Menor Cueto & $(1,1)$ & $(1,2)$ & $(1,3)$ & $(1,4)$ \\
\hline D1ferenolacko & $(2,1)$ & $(2,2)$ & $(2,3)$ & $(2,4)$ \\
\hline
\end{tabular}

Figura 4:Combinaçōes possíveis entre as Estratégias Competitivas e as Prioridades Competitivas da Manufatura 
quisa de campo em 12 empresas representativas localizadas no estado de São Paulo durante o segundo semestre de 1993. Os principais dados levantados referentes às Estratégias Competitivas e Prioridades Competitivas da Manufatura nas empresas pesquisadas são descritos a seguir.

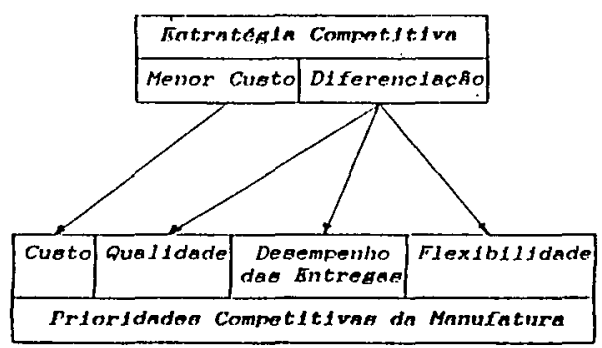

Figura 5:Combinações consideradas viáveis entre as Estratéglas Competitivas e as Prioridades Competitivas da Manufatura

\section{Estratégias Competitivas e Prioridades Competitivas da Manufatura nas Empresas Pesquisadas}

A pesquisa de campo realizada por estes autores durante o segundo semestre de 1993 teve um caráter exploratório, ou seja, tratou-se de uma pesquisa que não se preocupou em seguir os rigores da ciência estatística, para que a mesma pudesse ser viabilizada. Foram pesquisadas 12 empresas representativas sediadas no estado de São Paulo, levantando-se dados tipicamente gerenciais. Esses dados foram levantados em entrevistas realizadas junto ao executivo responsável pela Manufatura nessas empresas e baseadas num questionário previamente elaborado. A figura 6 apresenta as empresas pesquisadas, sem entretanto identificá-las.

A pesquisa abrangeu um conjunto de empresas bem heterogêneas no tocante ao faturamento/ano, o qual variava de 25 a 150 milhōes de dólares. Dessas empresas, 8 eram de capital multinacional e 4 de capital nacional.

\section{Dados sobre as Estratégias Competitivas das Empresas}

Praticamente todas as 12 empresas estudadas concorriam no mercado através das

\begin{tabular}{|c|c|}
\hline Empreana & $\begin{array}{l}\text { Ramo de Atuacho } \\
\text { (princlfal) }\end{array}$ \\
\hline 01 & $\begin{array}{l}\text { maguinas de movimentecso } \\
\text { o traneporte de materlale }\end{array}$ \\
\hline 07 & olotirnckomont:lenn \\
\hline 03 & $\begin{array}{l}\text { componentor p/ I ndúetrio } \\
\text { de eletrodomést lcos }\end{array}$ \\
\hline 01 & eletrodométicos \\
\hline 05 & $\begin{array}{l}\text { máquines de movimentacso } \\
\text { o tranoporte de materialo }\end{array}$ \\
\hline 06 & ogulpamentoe mecantcoe \\
\hline 07 & bene de onfital \\
\hline $\mathbf{O B}$ & $\begin{array}{l}\text { magulnan de movimentecan } \\
\text { e traneporte de materlate }\end{array}$ \\
\hline 09 & melharte \\
\hline 10 & autopecas \\
\hline 11 & maquinas p/ agro-1ndúgtria \\
\hline 12 & valvulas induetriale \\
\hline
\end{tabular}

Figura 6: Apresentação das empresas pesquisadas

duas estratégias genéricas relatadas anterioriormente (menor custo e diferenciação), embora aparentemente suas estratégias não fossem o resultado de um processo de decisão explícito e sistematizado. A maioria dos dirigentes entrevistados já conhecia o modelo de Porter (1985), o que tornou relativamente fácil de relacionar as Estratégias Competitivas através das quais seus produtos competiam no mercado.

Das 12 empresas pesquisadas, apenas duas empresas de capital nacional não se enquadravam no modelo de Unidades de Negócios pertencentes a uma Corporação/Grupo, mesmo ambas possuindo mais do que uma unidade fabril. Por sua vez, das 8 empresas de capital multinacional pesquisadas, todas trabalham sob esse modelo organizacional. A figura 7 apresenta os resultados da pesquisa no tocante às Estratégias Competitivas das empresas pesquisadas,é interessante notar que:

odois terços das empresas pesquisadas procurava aplicar uma única Estraté- 


\begin{tabular}{|c|c|c|}
\hline & \multicolumn{2}{|c|}{ Eatratégla Competitiva } \\
\hline Empresal & Menor Custo & Diferenclactio \\
\hline 01 & - & para todos os produtos \\
\hline 02 & para 2 produtoo & para 2 produtoo \\
\hline 03 & - & para todos os produtos \\
\hline 04 & para todos os produtos & - \\
\hline 05 & pars todos os produtos & - \\
\hline 06 & para todos os produtos & - \\
\hline 07 & para 1 produto & para 2 produtos \\
\hline 08 & - & para todos os produtos \\
\hline 09 & p/ produtoe "populare日" & para roucoe produtoe \\
\hline 10 & - & para todoes os produtos \\
\hline 11 & - & pera todos os produtas \\
\hline 12 & $\begin{array}{l}\text { p/ modelos a seram use- } \\
\text { dos om ambientes rusti- } \\
\text { cos, menos exirentes }\end{array}$ & $\begin{array}{l}\text { p/ modelog a serem usa- } \\
\text { dos em ambienteg peri- } \\
\text { gosos, male exlgenteo }\end{array}$ \\
\hline
\end{tabular}

Figura 7: Estratégias Competitivas das empresas estudadas

gia Competitiva dentro da mesma Unidade de Negócios. Dessas empresas $62 \%$ aplicavam a estratégia de díferenciação e $38 \%$ aplicavam a estratégia de menor custo/preço;

- um terço das empresas pesquisadas aplicava estratégias competitivas distintas, dentro da mesma Unidade de Negócios, dependendo da linha de produtos em questão.

- a empresa 2 procurava competir através de menores custos/preços em seus produtos considerados "populares" e em produtos que serviam de componentes para produtos de outras empresas; por outro lado procurava competir com produtos diferenciados, onde seus produtos tradicionalmente mantinham uma reputação de terem mais qualidade que os concorrentes;

- a empresa 7 procurava competir através da diferenciação (principalmente em função da tecnologia envolvida) em seus produtos onde a grande maioria dos concorrentes não tinha condições para aplicar a mesma estratégia; por outro lado ela procurava competir através de menores custos/preços onde sofria a concorrência de produtos im- portados;

oa empresa 9 procurava competir através de menores custos/preços em seus produtos considerados "populares"; competia também através da diferenciação em alguns poucos produtos, onde a distinçăo era obtida principalmente através do uso de melhores materiais e qualidade final dos mesmos;

o a empresa 12 procurava competir através de menores custos/preços em seus produtos considerados de utilização "menos nobre", onde o nível de concorrência é grande; competia também através da diferenciação em produtos "mais nobres", onde o nível de exigências quanto à utilização pode permitir a prática de preços maiores em troca de um nível tecnológico maior dos mesmos.

\section{Dados sobre as Prioridades Competitivas da Manufatura das Empresas}

Levantar os dados a respeito das Prioridades Competitivas da Manufatura foi mais difícil que levantar os dados sobre as Estra- 


\begin{tabular}{|c|c|c|c|c|}
\hline \multirow[b]{2}{*}{ Empresa } & \multicolumn{2}{|c|}{ Prlorldade } & \multicolumn{2}{|l|}{ Compet 1 t 1 va } \\
\hline & Menor Custo & Qualtdade & $\begin{array}{c}\text { Desempenho } \\
\text { das Entregas }\end{array}$ & Flextbllidade \\
\hline 01 & 1 & 2 & 3 & 4 \\
\hline 02 & 1 & 3 & 2 & 1 \\
\hline 03 & 4 & 1 & 2 & $\mathbf{3}$ \\
\hline 04 & 1 & 2 & 3 & 4 \\
\hline 06 & 1 & 2 & 3 & 4 \\
\hline 06 & 1 & 1 & 1 & 2 \\
\hline 07 & 1 & 1 & 1 & 1 \\
\hline $0 B$ & 4 & 1 & 2 & 3 \\
\hline 09 & 1 & 1 & $\mathbf{3}$ & 2 \\
\hline 10 & 2 & 1 & 3 & 4 \\
\hline 11 & 4 & 2 & 1 & $\mathbf{3}$ \\
\hline 12 & 1 & 2 & 3 & 4 \\
\hline Total & $(22)$ & $(19)$ & $(27)$ & (38) \\
\hline Ordem & $2 \underline{a}$ & $1 \underline{\theta}$ & 39 & 49 \\
\hline
\end{tabular}

Figura 8: Prioridades Competitivas da Manufatura

tégias Competitivas. Isso porque, a maioria das empresas não possuía uma definição explícita de suas Prioridades Competitivas. As prioridades foram então relatadas pelos dirigentes entrevistados, através da atribuição de uma escala de pesos de 1 a 4 (1 para a prioridade primária, 2 para a secundária, etc.) às quatro prioridades consideradas.

A figura 8 relata como as Prioridades Competitivas da Manufatura foram atribuídas em cada uma das empresas.
$\mathrm{Na}$ figura 8, considerando-se o número de vezes em que uma prioridade foi citada como sendo a Prioridade Competitiva 1,2,3 e 4 da Manufatura, tem-se que a prioridade Menor Custo aparece mais vezes no primeiro lugar, seguida da Qualidade, Desempenho das Entregas e Flexibilidade, conforme mostra a figura 9.

Os dados sobre as 12 empresas pesquisadas e apresentados nas tabelas 3 e 4 , sugerem então que:

\begin{tabular}{|c|c|c|c|c|}
\hline $\begin{array}{c}\text { Como Prio- } \\
\text { ridado }\end{array}$ & Menor Custo & Qual dado & $\begin{array}{c}\text { Deasmpenho } \\
\text { das Entrogao }\end{array}$ & Flexibilidado \\
\hline 1 & 8 & 6 & 3 & 1 \\
\hline 2 & 1 & 6 & 3 & 2 \\
\hline 3 & 0 & 1 & 6 & 3 \\
\hline 4 & 3 & 0 & 0 & 6 \\
\hline
\end{tabular}

Figura 9:Número de vezes em que foi cilada como sendo a Prioridade Competitiva 1,2,3 e 4 da Manufatura 
- o menor custo foi com maiss freqüência considerado a primeira Prioridade Competitiva da Manufatura; quando não foi apontado como sendo o primeiro, ele parece ser renegado ao quarto e último nível das Prioridades;

- a Qualidade foi considerada a prioridade mais importante das quatro consideradas, visto que na maioria das vezes ela foi citada como sendo a prioridade primária ou secundária da Manufatura;

- o desempenho das entregas foi considerado a terceira Prioridade da Manufatura, podendo em certos casos saltar para segunda e primeira posição;

- a flexibilidade parece que ainda tende a ser a quarta Prioridade da Manufatura, mesmo em empresas onde virtualmente se esperava uma posição de mais destaque para a mesma.

É importante ressaltar que a Estratégia Competitiva mais freqüente foi a diferenciação, enquanto que Prioridade Competitiva da Manufatura primária mais freqüente foi o Menor Custo, o que a princípio não coincidiu integralmente com a expectativa de integração desses dois niveis ilustrados pela figura 5. A empresa 1 , por exemplo, procurava utilizar uma Estratégia Competitiva de diferenciação e, ao mesmo tempo, tinha como Prioridade Competitiva primária da Manufatura o menor custo. Por outro lado, a empresa 10 que se mostrou ser, sob diversos parâmetros, a empresa com o melhor desempenho dentre as empresas estudadas apresentava uma integração entre os dois níveis perfeitamente dentro das expectativas do modelo proposto.

A pesquisa de campo realizada também proporcionou que outras conclusōes fossem tomadas a respeito da amostra de empresas estudadas. As principais estão sumarizadas a seguir.

\section{Conclusões}

As principais conclusões a que se pôde chegar sobre os dados da pesquisa de campo realizada são:
- inexistência de estratégias formais nas empresas

$\mathrm{Na}$ grande maioria das empresas pesquisadas, praticamente não se encontrou a definição de estratégias formais, principalmente naquelas de capital nacional. Os dados levantados sobre as Estratégias Competitivas e da Manufatura (principalmente sobre as Prioridades Competitivas) tendem a refletir a posição do dirigente industrial entrevistado e não necessariamente fazem parte do conteúdo de uma estratégia formalmente estabelecida.

Entretanto, na maioria das empresas estudadas (principamente nas de capital multinacional), foi possivel detectar um certo grau de proximidade com o conceito de Estratégia Competitiva definido por Porter (2).

. desconhecimento do conceito de Estratégia da Manufatura :

O conceito de Estratégia da Manufatura, tal como tem sido definido pela maioria da literatura mundial, era praticamente desconhecido pelas empresas pesquisadas. Entretanto, aparentemente todas sabiam, por exemplo, da importância das Prioridades Competitivas da Manufatura, porém nāo as conheciam contextualizadas de uma forma tal qual foi definida neste trabalho.

- existência de vários programas de ação não pertencentes a um estratégia formal

Praticamente todas as empresas pesquisadas estavam implementando vários Programas de Ação, porém predominantemente na linha das "necessidades competitivas", ou seja, não colocados como programas pertencentes a uma Estratégia da Manufatura formal. Um exemplo típico desses programas era exatamente a implementação de procedimentos referentes à gestão da qualidade e capazes de dar à empresa o cobiçado certificado da norma ISO 9000.

- pouca integraçāo da manufatura com a unidade de negócios e a corporação

Nas empresas pesquisadas, mesmo nas de capital multinacional, aparentemente ainda existia muito pouco contacto/integra- 
ção entre a Manufatura e a Unidade de $\mathrm{Ne}$ gócios e a Corporação à qual ela pertencia. Todavia, o processo vigente de abertura da economia brasileira parecia trazer boas perspectivas nesse sentido, principalmente no tocante ao desenvolvimento de produtos e processos.

\section{Referências Bibliográficas}

PIRES, S.R.I., "Integraçāo do Planejamento e Controle da Produçāo a uma Estratégia da Manufatura", Tese de Doutorado, Escola de Engenharia de São Carlos/USP, 1994.

PORTER, M., "Competitive Advantage Creating and Sustaining Superior Performance", Free Press, New York, 1985.

SKINNER, W., "Manufacturing-Missing Link in Corporate Strategy", Harvard Business Review, May-June, 136- 145, 1969.

SKINNER, W., "The Focused Factory", Harvard Business Review, May-June, 113121, 1974

WHEELWRIGHT, S.C.,"Manufacturing Strategy: Defining the Missing Link", Strategic Management Journal, Vol. 5, 77- 91, 1984. 